\title{
Osteoporosis risk - think twice about bone density in Ethiopians African Americans
}

\begin{abstract}
Objective: The risk of an osteoporotic fracture is well described and readily available in developed nations where 1 in 3 women and 1 in 5 men will experience an osteoporotic fracture. The risk of an osteoporotic fracture in developing nations is less known. Considerations of skeletal and non-skeletal factors may not fully describe risk of osteoporotic fractures. The purpose of this manuscript is to highlight the risk found in Ethiopians and Ethiopian immigrants.
\end{abstract}

Discussion: In the United States, bone mass density is greatest in black women and least in Asians. Osteoporosis incidence from greatest to least in Unites States is as follows: Native Americans, Asians, Hispanics, Caucasians, and blacks. Data is not available in many developing nations. For example, for Ethiopians data is not available on fracture risk. Thus, Ethiopians and Ethiopian immigrants when seeking medical attention may be considered black. Yet, Ethiopians may have a high prevalence of osteoporosis.

Conclusion: Risk factors for osteoporosis must be considered when examining and treating patients. Screening for less known risk factors such as low calcium intake, prolonged lactation, smoking, and excessive alcohol consumption must be considered for primary, secondary, and tertiary prevention.

Keywords: Ethiopia, osteoporosis, bone density
Volume 4 Issue $3-2019$

\author{
Barbara Billek-Sawhney \\ Department of Physical Therapy, Butler Health System, Slippery \\ Rock University, USA
}

\begin{abstract}
Correspondence: Barbara Billek-Sawhney, Slippery Rock University, Physical Therapy Program, Slippery Rock, PA, I6057,
\end{abstract} USA, Email barbara.billek@sru.edu

Received: April 13,2019 | Published: May 17, 2019

\section{Introduction}

The population of the world in 2017 was 7.6 billion. By 2030, it is expected to be 8.6 billion. $^{1}$ Between 2017 and 2050, 50\% of the world's population is expected to be in 9 countries, see Table $1 .{ }^{1}$ With the decrease in the world's fertility rate coupled with a simultaneous increase in the aging population, there is a silver tsunami or graying of the world. ${ }^{1}$

Table I Half of the world's population is expected to be in these countries between 2017 and $2050^{\prime}$

India
Nigeria
Democratic Republic of the Congo
Pakistan
Ethiopia
United Republic of Tanzania
United States of America (USA)
Uganda
Indonesia

Listed in order of the expected contribution to the growth.

The percent of the population 60 years of age and older is expected to double between 2017 and 2050. By 2100, it should triple. ${ }^{1}$ By 2050 , it is expected that $35 \%$ of the European population will be 60 years and older. Conversely, at the other end of the spectrum for the older adult population growth is Africa. In Africa, the percentage of the population over the age of 60 is expected to increase from the current $5 \%$, to $9 \%$ by 2050 , and $20 \%$ by $2100 .^{1}$

One in 4 older adults fall annually. ${ }^{2}$ The consequences of falls are both physical and physiological. Physically, the consequences of falls include fractures, bruises, and other (lacerations, dislocations, sprains, pains, and hematoma. Physiologically the effects of falls, reported from 87 publications, include, death/morbidity, functional decline, inactivity, functional dependency and loss of autonomy, depression, loss of self-confidence, and a loss of self-efficacy. ${ }^{3}$ In US adults, age 50 and above, approximately 1 in 2 women and up to 1 in 4 men, will sustain an osteoporosis fracture ${ }^{4}$ In developing nations, the incidence of osteoporosis, frequency of falls, and their impact is not well known. Globally, the risk of having an osteoporotic fracture is 1 in 3 women and 1 in 5 men. ${ }^{4,5}$ Risk increases with advancing age. ${ }^{4,5}$ The lifetime risk of a fragility fracture is $50 \%$ in Caucasian women and $13 \%$ in Caucasian men. The overall mortality of a hip fracture is $15-30 \%$ with the majority occurring within 6 -months of a fracture. ${ }^{6}$ Therefore, with the graying of the world, the incidence of fracture and associated mortality will increase.

Since the development of the FRAX ${ }^{\circledR}$, the Fracture Risk Assessment Tool in 2011, more than 24.8 million individuals have calculated their individualized fracture risk. The FRAX ${ }^{\circledR}$ is a wellknown web and paper-based tool to calculate the 10-year fracture risk based on individual risk factors. Models are available for 63 countries. $^{7}$ unfortunately, the tool is unable to consider some ethnic minorities because epidemiological information is not available. The FRAX calculation tool can be applied for Asia, Europe, Middle East and Africa, North America, Latin America, and Oceania. Within the Middle East and Africa regions, data is available for only the countries of Abu Dhabi, Iran, Jordan, Kuwait, Lebanon, Morocco, Palestine, and Tunisia.? 
When, a person's country is not listed, the user is advised to use the country most like the user's country. ${ }^{7}$ unfortunately for the country of Ethiopia, it would be difficult to decide which country Ethiopians should select. Should Ethiopians consider selecting Tunisia or US black or another country? If a health care provider cares for an Ethiopian immigrant, would the health care provider be aware of the patient's potential risk for osteoporosis? Would the health care provider considered the Ethiopian patient to be black and believe the patient to have the greatest bone density? Within Ethiopia the diversity is pronounced and variable with variability in languages, norms, culture, skin color, and physic. This brief paper will stress the need to look at all risk factors associated with osteoporosis when working with individuals from Ethiopia.

\section{Clinical considerations}

Ethiopia has a reported net migration rate of 0.2 migrants $/ 1,000$ population and a population of more than 108 million as of $2018 .{ }^{8}$ The number of immigrants from Sub-Saharan Africa to United States (U.S.) has grown. In 1980 there were 130,000 immigrants; in 2015 this number escalated to 1.7 million. ${ }^{9}$ Migration to other countries has also occurred. The number of immigrants in 2015 for Ethiopia was 229,000 or $13.3 \%$ of the total Sub-Saharan $(1,716,000) .{ }^{9}$

Although in 2004, the Surgeon General published a report on bone health and osteoporosis, addressing concerns related to ethnic minorities, racial minorities, and underserved populations, a subsequent report has not been published. ${ }^{10}$ Research by Cauley and colleagues on fracture risk in U.S. reveals fractures occur most in Caucasians and Native Americans and least in Asians, Africans, and Hispanics. A study of almost 20,000 U.S. women investigated 5 ethnic groups. Bone mass density was greatest in black women and least in Asians. Osteoporosis incidence from greatest to least was: Native Americans (11.9\%), Asians (10\%), Hispanics (9.8\%), Caucasians (7.2\%) and blacks (4.2\%). ${ }^{11}$ Irrespective of ethnicity, the risk of osteoporotic fractures increases as the number of risk factors increase. ${ }^{11}$

Although bone mass density is greatest among African Americans in U.S., ${ }^{1-13}$ health care providers should employ caution and not assume that an individual with dark pigmentation and being African American predicts lower fracture risk. In Israel the prevalence of osteoporosis and risk factors among Ethiopian immigrants in comparison to Israeli-born women relays a different story. Peled and colleagues found a high prevalence of osteoporosis (38.7\%) among Ethiopian immigrants compared to an incidence of 5.2\% among Israeli-born women. A strong association between osteoporosis and calcium intake during adolescent years, low body mass index, the prolonged duration of lactation among women during childbearing years, physical inactivity, and oral contraceptives was reported. ${ }^{14}$

Kahsay and colleagues researched osteoporosis in the Tigray region of Ethiopia. Participants included 130 osteoporotic individuals with a mean age of $60.9 \pm 10.1$ and 266 controls with a mean age of $46.9 \pm 8.7$ years. Rural residents were found to be 1.93 times more likely to develop osteoporosis than participants who resided in urban areas (adjusted odds ratio \{AOR 1.93 (95\% CI, 1.11.3.36). Decreased physical inactivity had the strongest association with AOR 3.53 (95\% CI,1.98 and 6.30. Key findings revealed relationships with milk consumption and smoking. Those residing in rural areas and smoking had a greater risk of developing osteoporosis. While individuals who had milk intake $>4$ times/week and performing work, which was physically demanding had a lower risk of osteoporosis. ${ }^{15}$
Balk and colleagues have investigated the dietary intake of calcium, globally. The highest incidence is in Iceland with $1233 \mathrm{mg} /$ day and the lowest is in Nepal at $175 \mathrm{mg} /$ day. Great variability is noted in the amount with Asia having the lowest incidence, followed by Africa and South America, and the greatest calcium intake in North America and Europe. ${ }^{16}$

Risk factors for the development of osteoporosis can be found in Table 2. These are classified into modifiable and non-modifiable risk factors. Major well-known resources related to osteoporosis were used to compile the Table 2; these include: the World Health Organization, International Osteoporosis Foundation, National Osteoporosis Foundation, and FRAX ${ }^{\circledR}$, the Fracture Risk Assessment Tool. Key risk factors identified by 3 of 4 of these resources include: age over 50 years of age, female gender, post-menopausal status in women, family history of osteoporosis or a hip fracture or fracture, low body mass index, low bone mass density, low dietary calcium intake, excessive alcohol consumption, cigarette smoking, and a sedentary lifestyle. $., 5,7,17$ The prolonged duration of lactation found in women during childbearing years described by Peled and colleagues in not listed in Table 2. ${ }^{14}$

Table 2 Risk factors associated with osteoporosis ${ }^{4,5,7,17}$

\begin{tabular}{|c|c|}
\hline Uncontrollable risk factors & $\begin{array}{l}\text { Controllable risk } \\
\text { factors }\end{array}$ \\
\hline $\begin{array}{l}\text { Being over the age of } 50(\mathrm{~F}, \mathrm{I}, \mathrm{N}) \\
\text { Female gender }(\mathrm{F}, \mathrm{I}, \mathrm{N})\end{array}$ & $\begin{array}{l}\text { Low dietary calcium } \\
\text { intake }(\mathrm{I}, \mathrm{N}, \mathrm{W})\end{array}$ \\
\hline Menopause (N) (premature $(\mathrm{I}, \mathrm{W})\}$ & $\begin{array}{l}\text { Vitamin D deficiency } \\
(\mathrm{I}, \mathrm{N})\end{array}$ \\
\hline $\begin{array}{l}\text { Family history of osteoporosis }(\mathrm{N})\{\text { specific to } \\
\text { hip fracture }(\mathrm{F}, \mathrm{I})\}\{\text { fracture in mother }(\mathrm{W})\}\end{array}$ & Excessive alcohol \\
\hline $\begin{array}{l}\text { Low body mass index / being small and thin } \\
(\mathrm{F}, \mathrm{I}, \mathrm{N}, \mathrm{W})\end{array}$ & $\begin{array}{l}\text { consumption }(\mathrm{F}, \mathrm{I}, \mathrm{N}, \mathrm{W})- \\
3 \text { or more units/day }(\mathrm{F})\end{array}$ \\
\hline Previous fracture $(\mathrm{F}, \mathrm{N})$ & $\begin{array}{l}\text { Cigarette smoking } \\
(\mathrm{F}, \mathrm{I}, \mathrm{N}, \mathrm{W})\end{array}$ \\
\hline Height loss $(\mathrm{N})$ & \\
\hline Asian or Caucasian race $(\mathrm{I})$ & $\begin{array}{l}\text { Dietary fruit and } \\
\text { vegetable deficiency }(\mathrm{N})\end{array}$ \\
\hline Estrogen use $(\mathrm{W})$ & Excess protein $(\mathrm{N})$ \\
\hline $\begin{array}{l}\text { Low bone mass density }(\mathrm{F}, \mathrm{I}, \mathrm{W}) \\
\text { High bone turnover (I) }\end{array}$ & Excess sodium $(\mathrm{N})$ \\
\hline Neuromuscular disorders (I) & Excess caffeine $(\mathrm{N}, \mathrm{W})$ \\
\hline Glucocorticoid long-term therapy (F,I) & $\begin{array}{l}\text { Sedentary lifestyle } \\
(\mathrm{I}, \mathrm{N}, \mathrm{W})\end{array}$ \\
\hline Rheumatoid arthritis (F,I) & \\
\hline Primary or secondary amenorrhea (I) & Losing weight $(\mathrm{N})$ \\
\hline Secondary osteoporosis (F) & Visual impairment (I) \\
\hline $\begin{array}{l}\text { Primary and secondary hypogonadism in men } \\
\text { (I) }\end{array}$ & $\begin{array}{l}\text { Frequent falls }(\mathrm{I}) / \text { trauma } \\
\text { (W) }\end{array}$ \\
\hline $\begin{array}{l}\text { Non-thiazide diuretic use }(\mathrm{W}) \\
\text { Diabetes mellitus non-insulin dependent }(\mathrm{W})\end{array}$ & $\begin{array}{l}\text { Strength quadriceps and } \\
\text { grip (W) }\end{array}$ \\
\hline Gastric surgery (W) & \\
\hline
\end{tabular}

Key FRAX®, the fracture risk assessment tool; (f), international osteoporosis foundation; (i), national osteoporosis foundation; (n), world health organization (W) 
When comparing the key risk factors identified by major organization to the research specific to Ethiopians the following risk factors were found decreased physical inactivity, milk consumption $<4$ times/week or low calcium intake during adolescent years, smoking, and low body mass index. The prolonged duration of lactation and use of oral contraceptives reported in the articles highlighted were not identified by key organizations.

\section{Recommendations}

Health care providers share a responsibility in primary, secondary, and tertiary prevention of osteoporosis, see Table 3. One should use caution and not presume that African Americans have a higher bone density and lower risk of osteoporosis based on skin color. Individuals emigrating to U.S. and other countries from poor countries face numerous obstacles to a healthy lifestyle that may have a profound impact on their bone density. It is recommended that when health care providers examine and treat immigrants from Ethiopia and other developing nations to consider more than the patients' skin color when evaluating for osteoporosis risk. Risk factors identified in Table 2 must be considered and action taken to address primary, secondary, and tertiary prevention of osteoporosis.

Table 3 Prevention defined and application to osteoporosis ${ }^{18,19}$

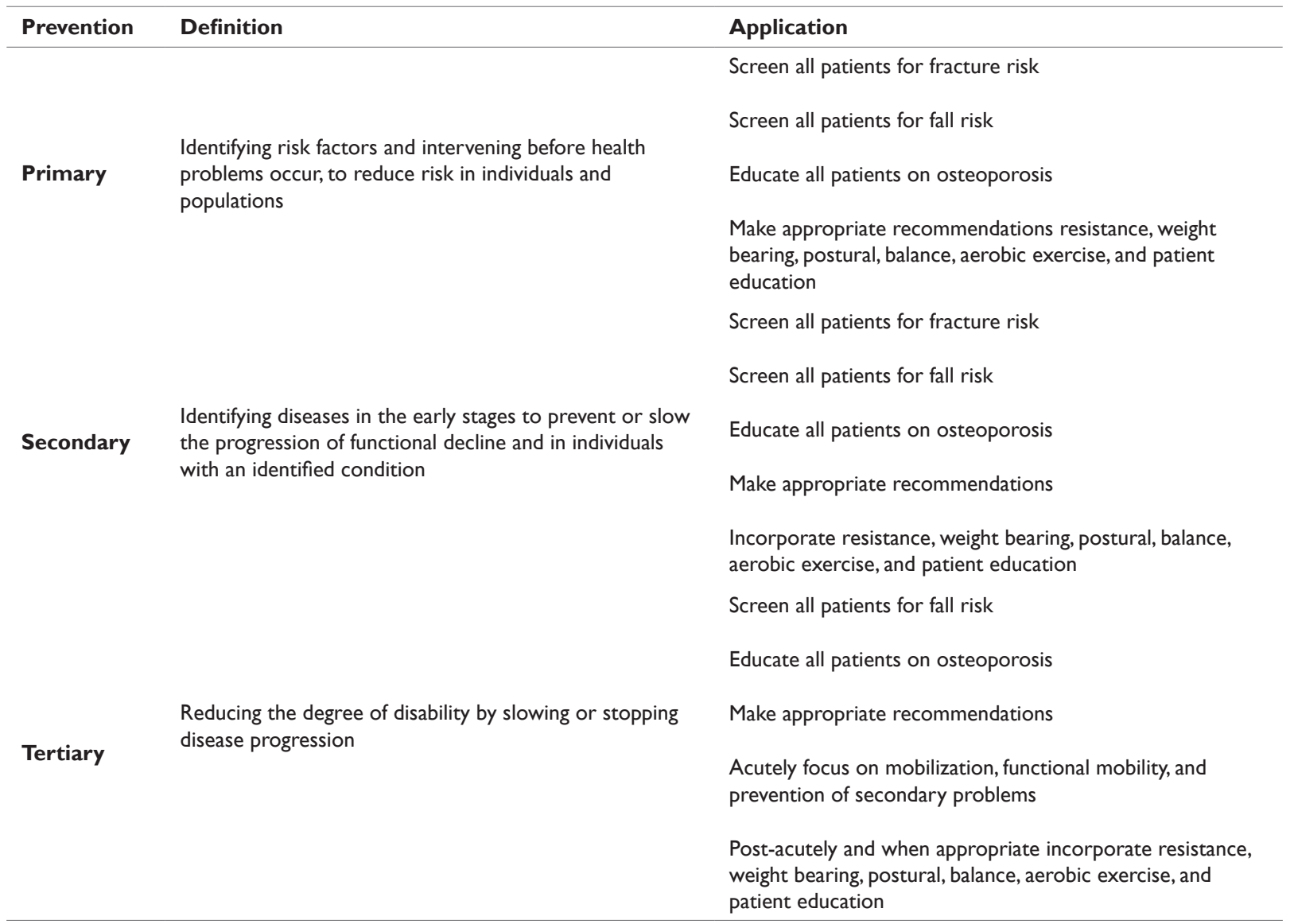

\section{Acknowledgements}

None

\section{Conflict of interest}

The authors declare no conflicts of interest.

\section{References}

1. https://www.un.org/development/desa/publications/world-populationprospects-the-2017-revision.html

2. https://www.cdc.gov/features/falls-older-adults/index.html

3. Terroso M, Rosa N, Marques T, et al. Physical consequences of falls in the elderly: a literature review from 1995 to 2010. Eur Rev Aging and Phys Act. 2013;11(1):51-59.

4. https://www.nof.org/patients/what-is-osteoporosis/
5. https://www.iofbonehealth.org/osteoporosis-musculoskeletal-disorders/ osteoporosis/diagnosis/fracture-risk-assessment

6. Masi L. Epidemiology of osteoporosis. clinical cases in mineral and bone metabolism. 2008;5(1):11-13.

7. https://www.sheffield.ac.uk/FRAX/index.aspx

8. https://www.migrationpolicy.org/country-resource/ethiopia

9. https://www.migrationpolicy.org/article/sub-saharan-african-immigrantsunited-states

10. United States public health service, office of the surgeon general. bone health and osteoporosis: a report of the surgeon general. U.S. Dept. of health and human services public health service office of the surgeon general, USA; 2004.

11. Cauley JA, Wu L, Wampler NS, et al. Clinical risk factors for fractures in multi-ethnic women. the women's health initiative. J Bone Miner Res. 2007;22:1816-1826. 
12. https://americanbonehealth.org/wp-content/uploads/2016/12/ BONESENSEonFractureRiskinAfricanAmericans_FINAL.pdf

13. Barrett CE, Siris ES, Wehren LE, et al. Osteoporosis and fracture risk in women of different ethnic groups. J Bone Miner Res. 2005;20:185-194.

14. Peled R, Daha D, Endevelt R, et al. Osteoporosis among Ethiopian immigrant women: A risk analysis. Arch Osteoporos. 2007;2:45-52.

15. Kahsay AB, Gashe FE, Debessai ZG, et al. Risk factors of osteoporosis among adults in Ethiopia, the case of Tigrai region. A case control study. J Public Health Epidemiology. 2014;62(2):92-1000.
16. Balk EM, Adam GP, Langberg VN, et al. Global dietary calcium intake among adults: A systematic review. Osteoporos Int. 2017;28(12):33153324.

17. http://apps.who.int/iris/bitstream/handle/10665/42841/WHO_TRS_921. pdf? sequence $=1 \&$ isAllowed $=\mathrm{y}$

18. http://guidetoptpractice.apta.org/

19. https://www.cdc.gov/pictureofamerica/pdfs/picture_of_america_ prevention.pdf 